
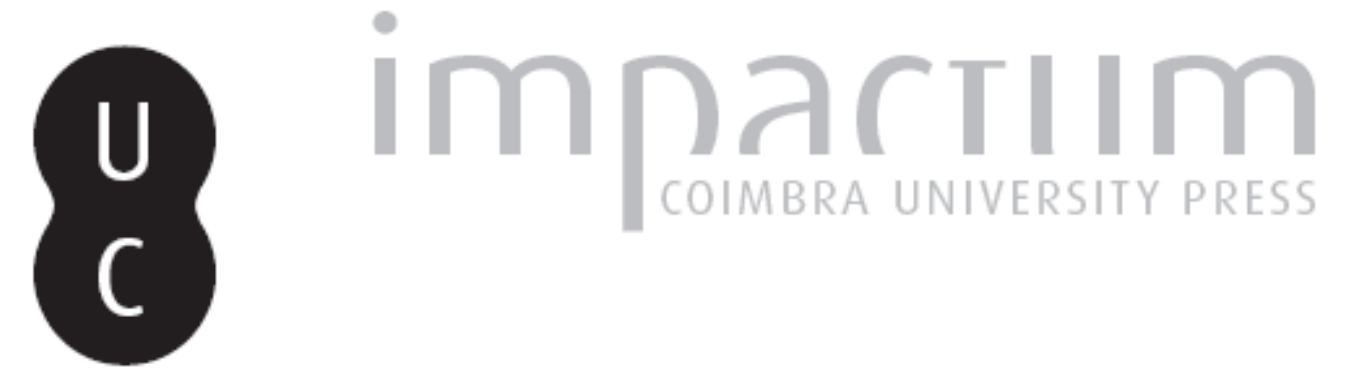

\title{
Da audiência presumida à audiência real: influência das métricas nas decisões editoriais dos jornais online
}

Autor(es): $\quad$ Canavilhas, João; Torres, Vitor; Luna, Diógenes de

Publicado por: Imprensa da Universidade de Coimbra

URL persistente:

URI:http://hdl.handle.net/10316.2/39192

DOI:

DOI:http//dx.doi.org/10.14195/2183-6019_2_10

Accessed : $\quad$ 26-Apr-2023 12:39:52

A navegação consulta e descarregamento dos títulos inseridos nas Bibliotecas Digitais UC Digitalis, UC Pombalina e UC Impactum, pressupõem a aceitação plena e sem reservas dos Termos e Condições de Uso destas Bibliotecas Digitais, disponíveis em https://digitalis.uc.pt/pt-pt/termos.

Conforme exposto nos referidos Termos e Condições de Uso, o descarregamento de títulos de acesso restrito requer uma licença válida de autorização devendo o utilizador aceder ao(s) documento(s) a partir de um endereço de IP da instituição detentora da supramencionada licença.

Ao utilizador é apenas permitido o descarregamento para uso pessoal, pelo que o emprego do(s) título(s) descarregado(s) para outro fim, designadamente comercial, carece de autorização do respetivo autor ou editor da obra.

Na medida em que todas as obras da UC Digitalis se encontram protegidas pelo Código do Direito de Autor e Direitos Conexos e demais legislação aplicável, toda a cópia, parcial ou total, deste documento, nos casos em que é legalmente admitida, deverá conter ou fazer-se acompanhar por este aviso.

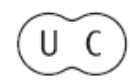


revista de comunicação,

jornalismo e espaço público

2

Periodicidade

Semestral

Imprensa da Universidade de Coimbra Coimbra University Press

\section{mediapolis}

tema

os desafios dos media

de serviço público

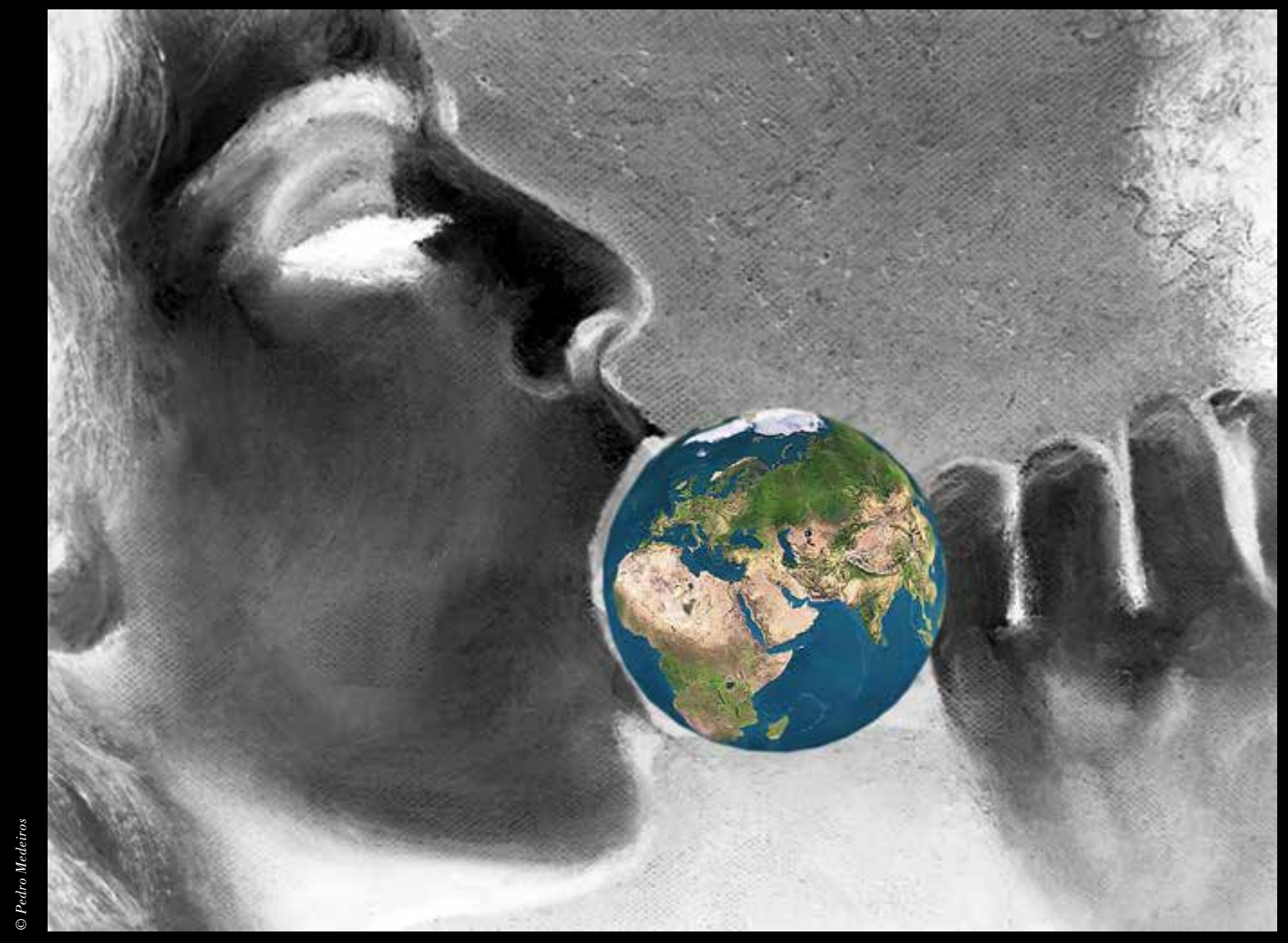




\section{João Canavilhas}

Universidade da Beira Interior (UBI)

\section{Da audiência presumida à audiência real:}

Vitor Torres

Universidade Federal da Bahia (UFBA)

vitortorres.mid@gmail.com

Diógenes de Luna

Universidade Federal do Cariri (UFCA

diogenesdeluna@cariri.ufc.br

\section{Influência das métricas nas decisões editoriais dos jornais online}

From assumed public to real public: The influence of the metrics on the editorial decisions of online media

\section{Resumo}

Este trabalho procura responder a uma questão que tem vindo a ganhar importância no cenário online: em que medida a audiência influencia as decisões editoriais numa organização jornalística. Para responder à questão, o trabalho começa por introduzir o conceito de métricas. Segue-se a revisão bibliográfica que aborda os processos de gatekeeping e gatewatching, aprofundando seguidamente questões relacionadas com a mensurabilidade da audiência no jornalismo Web. A parte empírica do trabalho é constituída pela análise das entrevistas realizadas a jornalistas de cinco organizações jornalísticas de Portugal e do Brasil. As conclusões indicam que as opções editoriais nas publicações online resultam de um processo em que a cultura profissional e as preferências do público (expressas em métricas de interpretação) são usadas de forma equilibrada.

Palavras-chave: Métricas, audiência, newsmaking, gatekeeping.
Abstract:

This paper tries to answer a question that has become paramount in the online scenario: how do the audience influences editorial decisions in a news organization. To answer this particular question, the present work begins by introducing the key concept of Web metrics. This is followed by a literature review which explains the gatekeeping and gatewatcher processes, expanding issues related to the measurability of the audience in Web journalism. The empirical part of the work consists of the analysis of interviews with journalists from five newspapers in Portugal and Brazil. The findings indicate that the editorial choices in online publications are the result of a process in which the professional culture and public preferences (expressed in the interpretation of Web metrics) are used in a balanced way.

Keywords: Web metrics, audiences, newsmaking, gatekeeping. 


\section{Introdução}

A finalidade da primeira página dos jornais em papel é idêntica à da página inicial (homepage) dos jornais na Web: classificar os acontecimentos noticiáveis e apontar as principais notícias através de uma hierarquia de apresentação dos conteúdos. Só que no caso do papel pretende-se incentivar o público a comprar o jornal, enquanto no online pode ter outros objetivos, pois aceder à homepage de um jornal é apenas uma das várias formas de aceder ao jornal. Hoje, percebe-se o enfraquecimento das homes enquanto produtoras de sentido (Barsotti e Aguiar, 2015) e há reflexos dessa mudança na cultura jornalística ${ }^{1}$. Por exemplo, se a notícia é distribuída isoladamente numa rede social, como se pode controlar a circulação do jornal neste contexto de distribuição por unidade?

1 Num documento de 2014, após constatar que os leitores acediam cada vez menos à sua página inicial, o The New York Times incentivou os editores e jornalistas a adotar estratégias de produção que atraíssem novas audiências. < http://www.niemanlab. org/2014/05/the-leaked-new-york-times-innovation-report-is-one-of-the-key-documents-of-this-media-age/>
Os meios de comunicação sofreram grandes mudanças com a digitalização e a expansão da internet, mas as questões relacionadas com a necessidade de conhecer a audiência são as mesmas de sempre: quando e como acede o utilizador aos conteúdos? Durante quanto tempo? Qual a idade, género e atividade profissional? Que habilitações literárias tem e qual o seu nível económico? Quais são os seus conteúdos preferidos? Estes são apenas alguns exemplos de perguntas cujas respostas interessam aos meios.

A necessidade de conhecer o leitor é fundamental para todos os meios de comunicação social, mas é particularmente importante no setor online devido às suas potencialidades de interação e personalização. Neste trabalho usaremos o termo "métricas"2 para designar o processo de medição e estudo dos hábitos da audiência, bem como o estudo do desempenho do site/ aplicação.

2 Do termo em inglês Web Metrics. Também chamada de Web Analytics, é usada por profissionais de monitorização e investigadores do Brasil e Portugal para apontar as diferentes maneiras de monitorizar os hábitos de consumo do utilizador e o desempenho dos produtos.
Usar métricas para mensurar um processo de distribuição ubíqua e permanente envolve o tratamento de três elementos: o objeto a mensurar, os resultados da mensuração e as operações empíricas de mensuração, ou seja, a forma como os dados brutos ganham significado (Henshaw, 2006). Uma métrica é um sistema de medição que quantifica uma tendência, uma dinâmica ou uma característica. Usam-se bases de dados para gerar métricas, procurando-se desta forma explicar fenómenos, diagnosticar causas, partilhar descobertas e projetar os resultados de eventos futuros (Farris, Bendle, Pfeifer \& Reibstein, 2010). No jornalismo é semelhante: as métricas são utilizadas para avaliar o desempenho dos sites, para perceber o ritmo e hábito de consumo de notícias e para planear estratégias de produção jornalística.

Mensurar as preferências e hábitos da audiência no consumo de informação não é novidade no jornalismo. Há décadas que existem dados cuja interpretação ajuda a traduzir o comportamento do leitor. A novidade é que, se antes os dados eram escassos, hoje são quantitativamente abundantes e 
qualitativamente precisos. Durante décadas, os mecanismos de recolha e tratamento destes dados eram pouco sofisticados, dificultando o tratamento das informações recolhidas. Atualmente, a digitalização permite o armazenamento em grandes escalas e garante eficiência na sua recuperação. As máquinas que gerem estes dados são preparadas para cruzar e relacionar a informação em tempo real, o que possibilita o desenvolvimento de novas formas de usar as métricas e, consequentemente, permite $\mathrm{o}$ aparecimento de diferentes tipos de análises e abordagens de investigação.

A preocupação da investigação universitária em relação às implicações que a audiência pode ter no fazer jornalístico também não é novidade. Na obra Deciding What's News, seminal sobre as rotinas produtivas, Herbert Gans (1979) registou comentários fundamentais para se estudar o comportamento dos jornalistas ao longo das últimas quatro décadas. Numa das conversas referidas pelo autor, um editor foi questionado sobre a importância de monitorizar a audiência e produzir conteúdos orientados para as preferências do leitor. A resposta foi elucidativa: "You do the show for a cell of people - the office staff, the wife, and the kids. These are the only know audience. I know we have twenty million viewers, but I don't know who they are. I don't know what the audience wants, and I don't care. I can't know, so I can’t care» (Gans, 1979: 234). A resposta deste editor, que espelha o cenário profissional da época, foi condicionada por duas ordens de razões: os dados imprecisos (o que causava dúvidas sobre sua relevância) e a forte tendência dos jornalistas para a inclusão do instinto e do faro jornalístico nas rotinas de trabalho.

O diagnóstico feito por Herbert Gans (1979) analisava uma época em que o paradigma da distribuição de informação jornalística se baseava na intenção de manter a atenção da audiência, sistema a que Jenkins, Ford e Green (2013) chamam «stickness», em alternativa ao atual paradigma de distribuição, a que chamam «spreadable» numa alusão à necessidade de orientar a produção do conteúdo para a distribuição em redes digitais. Este novo contexto, onde está inserida a noção de spreadable media, não exclui a existência do paradigma anterior: perceber as suas lógicas ajuda a compreender a emergência do poder, tanto técnico como cultural, conquistado pela audiência para partilhar informações.

Neste contexto «espalhável», os dispositivos móveis emergem como uma tecnologia definidora de novos padrões de produção, distribuição e consumo, sendo "objetos particularmente promissores no âmbito dos estudos voltados para o surgimento e desenvolvimento de inovações em jornalismo" (Palacios, Barbosa, Silva \& Da Cunha, 2015: 14). As funcionalidades presentes em smartphones e tablets, como a "opticabilidade" e "localibilidade" (idem, 2015), geram e potencializam affordances ${ }^{3}$ que são assumidas no contexto spreadable em que as preocupações são a monitorização e a medição da distribuição de informações jornalísticas. No jornalismo em papel, por exemplo, era possível saber a circulação de um jornal

30 termo é originado do verbo inglês to afford (conceder, dispor, proporcionar). A teoria das affordances é apresentada por James J. Gibson no final dos anos 1970 e tenta explicar como objetos são percebidos num determinado ambiente. É comum entre pesquisadores de língua portuguesa referir-se ao termo sem tradução. 
num determinado bairro, conhecendo as vendas dos quiosques naquela região. Atualmente, utilizando o sensor de GPS de um smartphone (localibilidade), é possível saber exatamente a posição do utilizador no momento em que lê um conteúdo específico. E quando um leitor regista um acontecimento com a câmara de seu tablet (opticabilidade) e envia a foto para uma organização, pode medir-se qualitativamente o nível de participação e colaboração.

As especificidades dessas novas plataformas têm potencialmente uma alta capacidade de geração ou reconfiguração de modos de produção, publicação, circulação e recirculação, consumo e recepção de novos conteúdos e novos formatos/gêneros, além de sugerirem e propiciarem o aparecimento de novos modelos de negócios. (Palacios, Barbosa, Silva \& Da Cunha, 2015:14).

As affordances assumidas neste novo contexto espalhável obrigam a repensar aspetos profissionais e teóricos relacionados com a medição da audiência. Como monitorizar e medir a distribuição de informações jornalísticas nesse ambiente espalhável e móvel? As métricas usadas nos meios tradicionais, como a televisão, a rádio e os jornais/revistas em papel, conseguem ajudar a compreender este novo contexto? As métricas utilizadas para mensurar audiências funcionam em jornais online? A quantidade de page views num site jornalístico, por exemplo, talvez não seja tão eficiente para diagnosticar o alcance da audiência como a possibilidade de medir o envolvimento dos leitores, o seu grau de atenção ou a influência de uma organização no mercado de notícias, por exemplo.

O objetivo deste trabalho é saber em que medida as métricas online influenciam as decisões editoriais numa organização jornalística, fazendo-se uma reflexão sobre as continuidades e as ruturas existentes no jornalismo contemporâneo. Inicialmente faz-se uma revisão da literatura sobre aspetos teóricos do newsmaking, especificamente acerca da teoria do gatekeeping e dos processos de seleção da notícia. Seguidamente são analisadas entrevistas com jornalistas de duas organizações jornalísticas brasileiras (Zero Hora e iBahia) e três portuguesas (Correio da Manhã, Observador e Público).

\section{Teoria do gatekeeping: da audiência presumida ao público personalizado}

Um jornalista diz em voz alta: "recorde de leitores neste momento!". A informação é comemorada em toda a redação e o trabalho continua. Um monitor, colocado em lugar de destaque na parede da redação, anuncia em tempo real as métricas de acesso ao jornal. Os gráficos mostram o número total de leitores, as notícias mais lidas, a plataforma de origem do utilizador e o tempo médio de permanência no site, entre outros dados. Dois profissionais, denominados "Gestores de Comunidades e Analistas Digitais", dividem a redação com os jornalistas, sendo os responsáveis por interpretar os dados e, através de relatórios, informar diretores e editores sobre a audiência do jornal. São ainda eles quem gere as publicações em redes sociais e interage com a audiência online. 
A interpretação das métricas tem consequências na relação dos leitores com os jornalistas, editores e diretores de organizações jornalísticas. "Os jornalistas constroem antecipadamente a audiência" (Vizeu, 2005: 94) e fazem isso recorrendo a vários processos. $\mathrm{O}$ conceito de audiência presumida no telejornalismo (Vizeu, 2005) procura identificar estas situações, afirmando que a construção da audiência é feita "a partir da cultura profissional, da organização do trabalho, dos processos produtivos, dos códigos particulares (as regras de redação), da língua e das regras do campo das linguagens para, no trabalho da enunciação, produzirem discursos" (Vizeu, 2005: 94). Nesta perspetiva, a audiência obedece de forma passiva às decisões editorais, consagrando o sistema de estímulo e resposta, possibilitando um "falso efeito de participação, na verdade uma participação ilusória porque as diversas vozes que constituem a sociedade não estão presentes" (Vizeu, Rocha \& Siqueira, 2010: 8). Cabe ao jornalista estruturar e selecionar as notícias.

A metáfora do gatekeeper (White, 1950) oferece aos investigadores em jornalismo uma metodologia para pensar e avaliar a forma como acontece esta estruturação e seleção. Parte-se da premissa que o jornalista, ao aplicar critérios de noticiabilidade e julgamentos de ordem subjetiva, decide que acontecimentos serão escolhidos para publicação (Shoemaker \& Vos, 2010). "O processo de gatekeeping começa quando um profissional da comunicação transforma a informação sobre um evento numa mensagem. Esse é o primeiro portão do evento." (Shoemaker \& Vos, 2010: 37). Shoemaker \& Reese (1996) delinearam um método de cinco níveis de influências sobre gatekeepers, ao qual chamaram "hierarquia de influência", argumentando que o processo de gatekeeping não acontece apenas num portão, mas em vários.

O primeiro nível, o de menor influência, está relacionado com fatores particulares do jornalista, nomeadamente experiências pessoais e crenças. Num segundo nível consideram-se as rotinas, incluindo orientações editoriais e processos produtivos. $\mathrm{O}$ terceiro nível concentra-se nas influências organizacionais. O quarto nível está relacionado com as forças externas aos media, incluindo a audiência, o controlo governamental e a concorrência de mercado. $\mathrm{O}$ último nível, e mais importante, é o chamado media ideology. Neste modelo, em que os níveis têm uma importância crescente, a audiência situa-se a meio da tabela.

Shoemaker e Vos (2010) também propõem cinco níveis para o estudo do gatekeeping em contextos contemporâneos. Semelhantes ao regime de produção de discursos de Vizeu (2005) e aos níveis de hierarquia de influência de Shoemaker e Reese (1996), o primeiro nível proposto pelos investigadores é o individual (a influência dos comunicadores individualmente, tais como antecedentes pessoais). O segundo são as rotinas (a influência das normas de comunicação, como a pirâmide invertida). O terceiro é o nível organizacional (a influência da dinâmica ao nível do grupo, como a propriedade dos media). O quarto nível é social institutional (a influência de fatores exteriores à organização, tais como anunciantes ou governo), e, por último, o sistema social (a influência da ideologia e da cultura).

O estudo das métricas em organizações jornalísticas posiciona-se no nível organizacional, uma vez que 
as novas dinâmicas de trabalho, influenciadas pelo acompanhamento sistemático e constante dos hábitos de leitura, são percebidas na redação. $\mathrm{O}$ aparecimento de novos profissionais nos jornais, como os gestores de comunidades e os analistas digitais, é um exemplo da mudança organizacional com impacto no processo de escolha da informação que deve passar a notícia e da que deve ser rejeitada. Equipas de monitorização, como especialistas em SEO, designers e programadores, ganham força nas decisões editoriais que acontecem em redações de todo o mundo. Canavilhas et al. (2014) chamam a estes novos elementos «tecnoatores», destacando que apesar de o jornalista ainda ter o lugar central no funcionamento da redação, "é evidente que a sua dependência em relação aos tecnoatores está crescendo" (Canavilhas et al., 2014, p.93).

Percebem-se também as alterações que a cultura das métricas pode provocar no nível social institucional, principalmente pela força externa que a audiência (e a sua presença nas redações simbolizada pelos dados oferecidos por softwares de web analytics) indica nas decisões editoriais e na hierarquização das informações oferecidas ao leitor. Revisões da teoria do gatekeeping apontam para a emergência de um audience gatekeeping (Lee, Lewis \& Powers, 2014) nas redes digitais, um processo em que os leitores conseguem facilmente distribuir os seus conteúdos preferidos, tornando-os visíveis. As ações de leitura, acesso e redistribuição indicam também a influência em decisões que se concentram em produtos externos ao site de uma organização jornalística, como as páginas no Facebook. Os jornais na Web já dedicam parte da sua atenção a esta participação da audiência quando incluem tops de "notícias mais lidas" e "mais partilhadas", começando a planear as estratégias de produção de notícias de acordo com as métricas de audiência.

Por tudo isto é cada vez mais interessante entender a forma como são monitorizadas e medidas a distribuição de informações jornalísticas online num ambiente espalhável/disseminável ${ }^{4}$ de distribuição e redistribuição de notícias. Neste contexto, como pode ser mensurada a distribuição das notícias online?

4 Spreadable media, termo cunhado por Jenkins, Ford e Green (2013).

\section{Mensurar a audiência online: métricas na distribuição das notícias}

O modelo de "hierarquia de influências" foi pensado numa conjuntura de media tradicionais, ambiente em que os jornalistas profissionais, de acordo com Gans (1979), se mantinham distantes da audiência. Atualmente, o jornalista recebe abundante informação relacionada com os hábitos dos leitores, com a forma como o seu conteúdo circula, podendo saber em tempo real quantas pessoas estão a ler a sua notícia, (ou a média diária, semanal, mensal, etc.), quanto tempo o leitor demorou a ler o conteúdo, o momento exato em que deixou de acompanhar uma reportagem ou quais as partes da reportagem mais lidas. Mudanças nos contextos culturais e tecnológicos aumentaram a concorrência e fragmentaram a audiência, pelo que as métricas podem evidenciar, ainda mais, a importância da audiência na hierarquia de influências.

A digitalização e a webização do jornalismo levaram ao aparecimento de novas formas de estudar o leitor e os seus hábitos, abrindo dessa forma 
a possibilidade de se verificar a forma como esse conhecimento interfere na produção jornalística. A gestão das bases de dados que recolhem informações sobre o comportamento online dos leitores é cada vez mais visível nas redações. Vários trabalhos de investigação (Moretzsohn, 2014; Lee, Lewis \& Powers, 2014; Tandoc Jr \& Thomas, 2014; Usher, 2013; Anderson, 2011) apresentam e discutem provas de que as organizações jornalísticas monitorizam e mensuram hábitos de leitura, interesses partilhados e preferências de conteúdo nos seus produtos. Todos os estudos salientam que os desejos do utilizador são rigorosamente avaliados nas redes digitais, por isso justifica-se perguntar: basear a escolha dos temas a abordar pelo jornal com base em audiências presumidas (the office staff, the wife, and the kids) tornou-se incoerente?

A circulação das notícias, expressa nas métricas observadas em programas como o ChartBeat ou o Google Analytics, leva a reflexões acerca do papel do gatekeeper secundário (Singer, 2014) que a audiência acaba por exercer, ao revalorizar as notícias, partilhando-as em plataformas digitais como as redes sociais. Ao redistribuir informações provenientes dos media online acaba por fazer um julgamento de valor sobre o conteúdo, além de influenciar as métricas calculadas pelos programas de monitorização.

The result is a two-step gatekeeping process, in which initial editorial decisions to reject or include an item in the news product are followed by users decisions to upgrade or downgrade the visibility of that item for a secondary audience (Singer, 2014: 67).

Ao determinar a visibilidade da notícia para uma audiência secundária, a audiência assume o papel de editor de conteúdos, embora fora da instituição jornalística. O papel social de comentar e redistribuir conteúdos coloca a audiência perante uma certa "autoridade editorial" em relação aos conteúdos que circulam dentro da sua comunidade de referência nas redes sociais. "Users now have the capability to make and implement what essentially are editorial judgments about what is worthy and what is less so, about what others should read and what they might as well ignore (Idem, p. 56)"'.

Bruns (2011) considera que estes utilizadores ativos realizam uma atividade de produção, ao realizar ações de curadoria dos conteúdos partilhados na sua rede social. Ao selecionar, partilhar e comentar estas peças jornalísticas, o utilizador acaba por assumir o papel de produsage, "como em projetos tão diversos como a Wikipedia e o desenvolvimento de fontes abertas" (Bruns, 2011: 124).

São práticas que modificam a lógica do gatekeeping interno do jornal e apontam para processos que já ultrapassam os limites físicos da redação do jornal e os limites humanos dos jornalistas. Bruns (2011) chama estes processos «gatewatching», confirmando mesmo num nível maior de envolvimento, as ações da audiência sobre as notícias, fazendo com que elas sejam importantes para o jornal no processo de redistribuição. A sua influência sente-se igualmente na produção de novos conteúdos porque o jornal tende a abordar futuramente temas semelhantes ao de peças já publicadas e bem recebidas e redistribuídas pela audiência nas redes sociais. 
No âmago de ambas estas mudanças que deixam o gatekeeping para trás está uma prática que se pode descrever ultimamente como gatewatching. Naturalmente, os usuários envolvidos em organizar e fazer a curation da torrente das matérias noticiosas disponíveis e das informações que têm valor como notícias que estão atualmente disponíveis em multidão de canais, não têm condições de guardar - de controlar - os portões de quaisquer destes canais; entretanto, o que eles têm condições de fazer é de participar em um esforço distribuído e folgadamente organizado de observar - de acompanhar - quais as informações que passam por esses canais (Bruns, 2011: 124).

No papel de gatewatching destacam-se as atividades de redistribuir, divulgar, contextualizar e de curador de material já existente. Esses dados, refletidos em programas informáticos fornecedores de métricas, são usados nas redações dos jornais online estudados neste trabalho. A motivação da audiência para desempenhar essas funções levanta a possibilidade de existir uma nova organização no processo de gatewatching ou secondary gatekeeping, a exemplo dos níveis do processo tradicional de gatekeeping descritos anteriormente por Shoemaker e Reese (1996) como uma "hierarquia de influências". Estas ações estarão entranhadas no nível mais importante (media ideology) e pode mesmo ocorrer noutros níveis, os quais serão alvo de uma investigação já em curso.

Mesmo com todo o aparato tecnológico disponível para recolha de informações sobre a audiência, certas decisões editoriais ainda passam pela subjetividade do editor e pela cultura profissional. Pelo menos é essa uma das conclusões de uma investigação conduzida por $\mathrm{Vu}$ (2014).

This, perhaps, is because the journalistic occupational pride of sustaining autonomy against any kind of non-professional influences made it harder for editors to admit that their editorial decision-making is affected by audience metrics (Vu, 2014: 1105).

$\mathrm{Vu}$ constata que os editores usam estes dados da audiência com a intenção de monitorizar o seu comportamento em relação aos conteúdos publicados online, além de planear a produção de conteúdos futuros e de lhes dar destaque na homepage do jornal.

Neste contexto é oportuno atualizar ou reinterpretar as velhas teorias desenvolvidas numa época marcada pelo paradigma dos mass media. Atualmente vive-se num período em que as práticas antigas convivem com novos procedimentos até aqui impossibilitados pelos limites tecnológicos. Para além do que foi referido por $\mathrm{Vu}$ (2014), destaque-se ainda o estudo de Warren Breed (1955) acerca da cultura profissional e da sua influência na produção das notícias. Os valores agregados à cultura profissional do jornalista apresentam-se dentro da redação, entre colegas de profissão. "Instead of adhering to societal and professional ideals, he re-defines his values to the more pragmatic level of the news-room group" (Breed, 1955: 335).

Neste contexto vale a pena refletir sobre o equilíbrio entre as decisões baseadas na cultura profissional e as que se fundamentam nos resultados das medições de audiências, ou seja, em que medida a mensuração 
da audiência (métricas) interfere nos processos de produção de notícias?

\section{O reflexo das métricas na produção de notícias}

A qualidade dos dados recolhidos é, aparentemente, suficiente para oferecer experiências de consumo hiperpersonalizadas. Sites que não produzem notícias e trabalham sob a lógica da agregação podem ser descritos como produtos jornalísticos hiperpersonalizados. Nestes produtos, o processo de hierarquização dos conteúdos noticiosos é automatizado e tem como principal e única força de hierarquização os dados e métricas de acesso e leitura (Torres, 2013). Em sites jornalísticos produtores de notícias esta lógica não aparenta ser fundamental. Trabalhos recentes apontam para uma significativa diferença entre as preferências do jornalista e do leitor (Lee, Lewis \& Powers, 2014; Bockzkowski \& Mitchelstein, 2013; Macgregor, 2007) "Namely, that journalists generally prefer "hard" news (public affairs) while consumers generally prefer "soft" news (nonpublic affairs)" (Lee, Lewis \& Powers, 2014: 506). Esta diferença, quando solucionada com o apoio de métricas de audiência, poderia provocar duas situações: 1) colocar em xeque o instinto e faro jornalístico em relação aos valores notícia; 2) destacar o papel preponderante de novos atores nas organizações jornalísticas, nomeadamente os analistas digitais e os gestores de comunidades.

Monitorizar os hábitos de leitura da audiência e orientar as estratégias de produção pelos resultados das métricas poderia provocar tensões no entendimento que certos profissionais têm dos factos a ser noticiados. Montserrat Domínguez, diretora do $\mathrm{Hu}$ ffington Post Espanha, aposta nessa estratégia fundamentalmente orientada pela monitorização do leitor: “A audiência é o objetivo e qualquer recurso é lícito para alcançarmos mais pessoas. Usamos métricas para cumprir esse objetivo: um maior número de leitores. Pela primeira vez sabemos exatamente quem nos lê", disse a jornalista em palestra de novembro de $2014^{5}$.

5 Montserrat Domínguez falou durante a abertura do VI Congresso de Ciberjornalismo e Web 2.0, em 2014, na Universidade do País Basco, Bilbao, Espanha.
Dentro das redações convive-se com o que Moretzsohn (2014: 71) considera ser "a busca do equilíbrio entre o que o leitor deseja e o que o jornal considera informação relevante: audiências são indiscutivelmente fundamentais, do contrário nenhuma empresa se sustenta, mas não podem ser obtidas a qualquer preço".

Parece claro, pois, que o público interfere nos processos de produção de notícias. O uso cada vez mais frequente de informações provenientes de programas específicos para traçar perfis e informar sobre os passos que os leitores dão dentro do ecossistema mediático digital demonstra a aproximação cada vez maior das preferências e gostos da audiência na definição dos conteúdos que serão publicados em jornais na Web, aplicações e redes sociais.

A força do jornal como instituição social aceite e culturalmente consolidada na sociedade ocidental é reforçada quando se questionam os publishers de jornais online sobre o peso e a influência de suas decisões editoriais. As escolhas, independentemente de abordarem temas pouco lidos ou que respondam às reais procuras da audiência, estão vinculadas 
às rotinas empresariais. A notícia segue um método institucionalizado de disponibilizar a informação aos consumidores, sendo produzida com base numa aliança entre instituições legitimadas e profissionais que trabalham nessas instituições (o jornal). "Thus it is inevitably a product of newsworkers drawing upon institutional processes and conforming to institutional practices" (Tuchman, 1978: 4).

Ao tratar da estrutura de uma rede de notícias ${ }^{6}$, Tuchman (1978) refere-se à recolha de informações, aos jornalistas e à tecnologia que possibilita o fluxo de informações entre as fontes e a redação. "This arrangement of intersecting fine mesh (the stringers), tensile strength (the reporters), and steel links (the wire services) supposedly provides a news blanket, insuring that all potential news will be found" (Tuchman, 1978: 22-23). Atualmente, esta rede amplia-se para além dos locais institucionais - fontes

60 termo news net remete para uma metáfora, apresentada por Tuchman (1978), para se referir à recolha de informações. Sugere que a rede de notícias equivale a uma rede de pesca: quanto menos espaços existirem entre os nós criados pela interseção entre as linhas da rede, maior é a possibilidade de capturar peixes mais pequenos. oficiais de informação - ao incluir as preferências do público que contribuem para o enquadramento da realidade quotidiana como notícia.

Na ecologia de múltiplas plataformas de produção e distribuição de notícias, percebe-se que a estrutura de recolha de informações, e respetiva rede tecnológica de apoio, se vai expandindo. Os novos atores inserem-se na teia mediática e ganham posição de destaque, influenciando mesmo as rotinas de produção de notícias. $\mathrm{O}$ público recetor dessas mensagens interage de forma ativa por meio de mecanismos de redistribuição e partilha de conteúdos, quer em redes sociais, quer dentro de sites ou aplicações. Mas em que medida as métricas de monitorização da audiência online influenciam a tomada de decisões editoriais numa organização jornalística?

\section{Gatekeepers e audiência: a perspetiva do equilíbrio entre cultura profissional e preferências do público}

Para responder a pergunta de partida (em que medida a audiência influencia as decisões editoriais numa organização jornalística) optou-se por recorrer à entrevista semiestruturada, uma técnica que permite recolher dados qualitativos num formato mais aberto e na linguagem do entrevistado, um aspeto muito importante num trabalho em que os entrevistados utilizam um jargão próprio da profissão. As entrevistas (presenciais, via Skype ou por email) foram realizadas nos meses de fevereiro e março de 2015 ,

Da amostra fizeram parte jornalistas e editores de jornais (online e em papel) portugueses e brasileiros. Em Portugal foram escolhidos o Correio da Manhã, o Observador e o Público. De acordo com a Alexa ${ }^{7}$ o Público é o diário de informação geral mais visitado em Portugal. O Correio da Manhã está igualmente entre os sites de informação mais visitados, sendo o jornal em papel mais lido no país. Por fim, o Observador é atualmente o jornal nativo digital mais acedido. No caso brasileiro foram escolhidos jornais de referência nas suas regiões. O Zero Hora, com sede em Porto Alegre, Rio Grande do Sul, é o

7 http://www.alexa.com 
maior jornal na região Sul do Brasil. O iBahia é um dos maiores jornais da região Nordeste e é também um nativo digital.

Uma das primeiras constatações é que existe hoje uma pressão resultante da aplicação de modelos de produção guiados por métricas de audiência. Para exemplificar, um jornalista do Público refere a prática de produzir títulos e leads diferentes para os mesmos conteúdos publicados no online e no papel.

Os títulos que lá estão são coisas muito etéreas e que não denunciam à partida sobre o que se trata a notícia. E isso muitas vezes passava para o site. Continua a passar, mas já passa menos. Hoje há o cuidado a fazer títulos para que eles sejam apanhados pelos motores de busca. Perde-se em poesia, mas ganha-se em eficiência (jornalista do Público, entrevista aos autores).

Outro exemplo de uma alteração nas redações foi avançado por um jornalista brasileiro, quando questionado sobre a pressão que as métricas causam no mercado jornalístico:
Nós temos metas: recirculação, meta de capa, cliques... todos os repórteres do 'digital' tem consciência disso, precisam estar "por dentro'. Eu diariamente envio um relatório de fechamento do meu dia, com minhas metas, as matérias que eu fiz, quantas pessoas estavam lendo essa matéria, quantos por cento ela teve de recirculação, se as pessoas a partir das minhas matérias navegaram pelo site e a audiência - como foi no Facebook (jornalista do Zero Hora, entrevista aos autores).

O jornalista fala de uma cultura que associa as tecnologias de monitorização ao fazer jornalístico, e afirma categoricamente a sua atual preponderância na produção de notícias:

Hoje o repórter não só escreve, não pensa somente na estória que vai contar, ele também precisa estar preocupado se deu certo, se é preciso mudar o título para melhorar o SEO, melhorar minha colocação nas buscas (jornalista do Zero Hora, entrevista aos autores).
Pelo seu lado, os editores entrevistados parecem habituados ao uso de métricas nas tomadas de decisões, tendo uma ideia precisa sobre o papel das métricas no jornalismo. De acordo com a definição operacional adotada neste trabalho, uma métrica é um sistema de mensuração que indica uma tendência, dinâmica ou característica. Mas não é apenas um dado isolado: usar métricas requer a interpretação dos dados para a sua aplicação, de forma estruturada, numa estratégia de publicação ou planeamento de produção e distribuição de notícias no ambiente online. Esta hipótese é confirmada por um editor brasileiro, quando questionado sobre o que é uma métrica de audiência. Métricas de audiência, ao meu entender e como víamos na redação, são dados seminais que balizam o desempenho do site e também sua produção de conteúdos (editor do iBahia, entrevista aos autores).

O conceito de mensurabilidade será então o resultado da interpretação de um dado numérico oferecido por programas informáticos de medição, a partir de relatórios oferecidos por analistas de media (social media). Este resultado é usado no planeamento, 
produção e distribuição de notícias em ambiente online.

Procurando saber em que medida a cultura das métricas influencia a tomada de decisões editoriais, o editor de um jornal português é categórico ao afirmar que estes dados influenciam decisivamente o dia-a-dia do jornal em relação às escolhas editorais. Ainda assim, a importância das métricas é relativizada:

Não significa que aquilo seja lido como uma tábua rasa, e não nos impede de fazer textos que nós sabemos, pelas mesmas razões, que as pessoas não vão agarrar. Mas nós agarramos nesses temas porque eles são importantes e porque, independentemente de haver muita ou pouca gente a ver, aquilo faz parte do que são as escolhas editoriais que o jornal quer fazer. $\mathrm{Na}$ escolha dos destaques na homepage procuramos sempre criar alguma dinâmica entre os temas que nós achamos muito importantes para as pessoas e aqueles temas que nós sabemos que as pessoas querem. Isso permite-nos fazer uma grelha mais diversificada do que se não tivéssemos o analytics

(Editor do Observador, entrevista aos autores).

Estes profissionais procuram fechar o espaço existente (gap) entre o que lhes diz o instinto e o que dizem as métricas.

Mas nem sempre as preferências da audiência são tidas em consideração, principalmente quando se trata de temas mais frios e fait divers, tal como refere outro editor de um jornal português. As decisões editoriais, neste caso, costumam focar-se no que dizem as métricas de audiência em relação a determinado assunto. Quando a notícia na qual se investe acaba por ser esquecida ou pouco acedida pelo público, as atualizações param. Outra, ou outras, ganham destaque e seguem o fluxo dinâmico das medições dos programas de métricas usadas na redação.

Se a métrica me disser "o que as pessoas querem ver é isto", então vamos ver se vale a pena investirmos nisso. Se alguém quer saber muito sobre o avião que caiu nos Alpes, nós agarramos e, se já investimos nisto, continuamos a investir. Mas se no site há outro assunto que nós gostamos, que achamos importante as pessoas terem acesso e até podemos medir se esse assunto interessa à opinião pública, então agarramo-lo (Editor do Correio da Manhã , entrevista aos autores).

A aproximação do jornalismo aos tecnoatores preocupados com a gestão das métricas agrada aos jornalistas:

Eu acho ótimo que se tenha uma equipe com essa função, que esteja a monitorizar o tráfego do site, o que está acontecendo fora do site e nas redes sociais. A diferença está no que será feito com esses dados (Jornalista do Público, entrevista aos autores).

A edição baseada no trabalho nas métricas é que o Tandoc Jr (2014) chama "de-selection". Este processo refere-se à decisão de quais serão os artigos que, após ultrapassarem os "portões" dos editores e serem publicadas nas homepages, serão 
substituídos por outras notícias aos longo do dia.

Apesar da valorização das métricas, a sua importância nas estratégias de publicação usadas em cada redação varia de meio para meio, com alguns casos em que ela é apenas mais um dado a ter em conta.

Isto funciona um bocado ad hoc, isto é, caso-a-caso e não de uma forma sistemática. $\mathrm{O}$ jornal onde trabalho tem escolhas editoriais muito próprias e, portanto, uma ação desse género (decisões editorias guiadas por métricas) muitas vezes entra em conflito com a política editorial. Nós temos essa postura, embora nem sempre seja verdade (jornalista do Público, entrevista aos autores).

Noutros casos as métricas são um elemento fundamental na definição das políticas editoriais. "Hoje uma redação digital sem métricas deixa de existir. Não é só contar estórias e ver o que acontece. Tem que ter esse pensamento de hierarquia" (jornalista do Zero Hora, entrevista aos autores).
Mas a posição mais habitual é uma certa moderação em relação à importância das métricas no funcionamento da redação:

Há coisas que surpreendem, porque, repare, volta e meia temos textos mais longos, especiais, feitos por nós com mais tempo, que à partida tu dirias que teoricamente não é daqueles temas votados ao sucesso. Mas por vezes percebes no ChartBeat que esses temas, os mais trabalhados por nós, são aqueles que as pessoas vão estar mais tempo a ler e têm mais aceitação. Isso tira um bocadinho aquele mito que nós temos na cabeça de que as pessoas só se interessam por coisas leves, isto não é verdade. E o ChartBeat mostra-nos isso permanentemente. Agora, acredito que há temas mais leves que as pessoas gostam de ler e há temas mais sólidos que menos pessoas gostam de ler, mas nós achamos importantes oferecê-los para aquelas pessoas que efetivamente queiram (...) É nesse cruzamento de coisas que nós decidimos o dia-a-dia (editor do Observador, entrevista aos autores).
Independentemente do maior ou menor valor atribuído às métricas no processo de produção de notícias, é indiscutível que os bons resultados de uma notícia agradam aos jornalistas. "As métricas na redação fazem com que o envolvimento dos jornalistas e de todas a pessoas que produzem conteúdo seja efetivamente mais visível. As pessoas perguntam se está a ter saída" (Editor do Correio da Manhã, entrevista aos autores).

Os dados e as métricas tornaram-se numa variável presente em todas as redações dos meios online. Ao fornecerem indicações preciosas sobre a audiência, estes dados permitem às empresas jornalísticas a identificação dos temas que mais interessam aos leitores e, dessa forma, atraírem mais publicidade. Mas também os jornalistas passam a ter uma imagem mais real do seu público e dos seus interesses, permitindo ajustes nas temáticas abordadas e na própria abordagem aos temas. 


\section{Considerações finais}

Ferramentas de análise de dados, como o Google Analytics ou o ChartBeat, oferecem hoje mecanismos que permitem ultrapassar o antigo cenário de um público presumido. As informações disponibilizadas pelas métricas da audiência online permitem traçar perfis de acesso e de utilizadores, oferecendo aos jornalistas um retrato fiel dos seus leitores e respetivos interesses temáticos.

Os tecnoatores que gerem tráfego e acessos às páginas das organizações jornalísticas têm hoje um papel fundamental dentro das redações digitais, acumulando a sua atividade com a função de arquitetar estratégias de produção, divulgação e distribuição de conteúdos jornalísticos noutras esferas que vão para além da homepage do jornal.

Este trabalho permitiu verificar que as decisões editoriais são muito influenciadas pelas análises de métricas, mas isso não significa que estejamos perante um modelo de jornalismo totalmente dependente das opções da audiência. $\mathrm{O}$ que se percebe é um modelo de produção de notícias caracterizado pelo equilíbrio entre as decisões editoriais (critérios de noticiabilidade tradicionais e cultura profissional jornalística) e as decisões orientadas pelos dados provenientes das métricas de audiência online.

Se as métricas ganharem maior importância, a ponto de exercerem pressão sobre as rotinas e decisões editoriais, a audiência transforma-se num constrangimento que se insere na cultura profissional e nas rotinas de produção de notícias, passando a fazer parte do sistema social que influencia os gatekeepers.

\section{Bibliografia}

Anderson, C. W. (2011). Between creative and quantified audiences: Web metrics and changing patterns of newswork in local US newsrooms. Journalism, 12,(5), 550-566.

Barsotti, A., \& Aguiar, L. (2015). O silêncio da primeira página no jornalismo on-line. Anais do III Colóquio Internacional Mudanças Estruturais no Jornalismo, 534-549.

Bendle, N. T., Farris, P. W., Pfeifer, P. E., \& Reibstein, D. J. (2010). Marketing metrics: The definitive guide to measuring marketing performance. New Jersey: Pearson Education.

Boczkowski, P. J., \& Mitchelstein, E. (2013). The news gap: When the information preferences of the media and the public diverge. Cambridge: MIT Press.

Breed, W. (1955). Social control in the newsroom: A functional analysis. Social Forces, 33 (4), 326-335.

Bruns, A. (2011). Gatekeeping, gatewatching, realimentação em tempo real: Novos desafios para o jornalismo. Brazilian Journalism Research, 7 (2), 119-140

Canavilhas, J., Satuf, I., Luna, D. De, \& Torres, V. (2014). Jornalistas e tecnoatores: Dois mundos, duas culturas, um objetivo. Esferas. 3 (5), 85-95

Gans, H. J. (1979). Deciding what's news: A study of CBS Evening News, NBC Nightly News, Newsweek and Time. Evanston: Northwestern University Press.

Henshaw, J. M. (2006). Does measurement measure up?: How numbers reveal and conceal the truth. Baltimore: JHU Press.

Jenkins, H. (2008). Cultura da convergência. São Paulo: Aleph. 
Jenkins, H., Ford, S., \& Green, J. (2013). Spreadable media. Creating value and meaning in a networked Culture. New York, London: New York University Press.

Lee, A., Lewis, S., \& Powers, M. (2014). Audience clicks and news placement: A study of time-lagged influence in online journalism. Communication Research, 41 (4), 505-530.

Macgregor, P. (2007). Tracking the online audience. Journalism Studies, 8 (2), 280-298

Moretszsohn, S. (2014). O "novo ritmo da redação" de $O$ Globo: A prioridade ao jornalismo digital e seus reflexos nas condições de trabalho e produção da notícia. Revista Parágrafo, 2 (2), 59-79.

Palacios, M., Barbosa, S., Da Silva, F. F., \& Da Cunha, R. (2015). Jornalismo móvel e inovações induzidas por affordances em narrativas para aplicativos em tablets e smartphones. In J. Canavilhas \& I. Satuf (Orgs), Jornalismo para dispositivos móveis: produção, distribuição e consumo (pp. 7-42). Livros Labcom.

Shoemaker, P., \& Reese, S. (1996). Mediating the message. White Plains. Longman.
Shoemaker, P., \& Vos, T. (2011). Teoria do gatekeeping: Seleção e construção da notícia. Porto Alegre: Penso.

Shoemaker, P., Johnson, P., Seo, H,. \& Wang, X. (2010). Readers as gatekeepers of online news: Brazil, China, and the United States. Brazilian Journalism Research, 6(1), 55-77.

Singer, J. (2014). User-generated visibility: Secondary gatekeeping in a shared media space. New Media \& Society, 16(1), 55-73.

Tandoc Jr, E. C. (2014). Journalism is twerking? How web analytics is changing the process of gatekeeping. New Media \& Society, 16 (4), 559-575

Tandoc Jr, E. C., \& Thomas, R. J. (2014). The ethics of web Analytics: Implications of using audience metrics in news construction. Digital Journalism, 3 (2), 243-258.

Torres, V. (2013). O curador de informação em produtos agregadores de notícias. (Dissertação de Mestrado). PósCOM/UFBA.

Tuchman, G. (1978). Making news. A study in the construction of reality. New York: The Free Press.
Usher, N. (2013). Al Jazeera English Online. Digital Journalism, 1, (3), 335-351

Vizeu, A. (2005). O lado oculto do telejornalismo. Florianópolis: Calandra.

Vizeu, A., Rocha, H. \& Siqueira, F. (2010). Telejornalismo: Da audiência presumida aos co-produtores da notícia. XXXIII Congresso Brasileiro de Ciências da Comunicação. Caxias do Sul. Consultado a 1 de junho de 2014. Disponível em http:// www.intercom.org.br/papers/nacionais/2010/resumos/R5-3124-1.pdf.

$\mathrm{Vu}, \mathrm{H}$. T. (2014). The online audience as gatekeeper. The influence of reader metrics on news editorial selection. Journalism. 15(8), 1094-1110.

White, D. C. (1950). The 'gate keeper': A case study in the selection of news. Jounalism Quarterly, 27, 383-390. 